\title{
Paternalism modernised
}

\author{
Gary B Weiss University of Texas
}

\section{Author's abstract}

The practice of paternalism has changed along with developments in medicine, philosophy, law, sociology and psychology. Physicians have learned that a patient's values are a factor in determining what is best for that patient. Modern paternalism continues to be guided by the principle that the physician decides what is best for the patient and pursues that course of action, taking into account the values and interests of the patient. In the autonomy model of the doctor-patient relationship, patient values are decisive. In the paternalistic model, they are but one among several factors the physician must consider in making a medical decision. Although difficult to practise because of limitations in empathising with another person, modern paternalism remains a way to achieve maximum patient benefit.

Medical practice has changed greatly in the past 40 years. Many previously untreatable illnesses (especially infections and cancer) can now be managed effectively and new technological marvels can sustain life. Physicians are expected to be aware of these new developments, being obliged to take continuing medical education courses, and they are subject to penalties in malpractice suits under the assumption that a competent physician keeps up to date. The physician who still treats syphilis with arsenicals, for example, would be judged incompetent, even though this was once standard therapy.

Parallel to new scientific achievements, notable developments have taken place in clinical ethics because of changes in clinical, philosophical, legal, sociological, and psychological practice. Paternalistic physicians hold firm to the principle that they should act to bring about maximum benefit for the patient, even at the expense of the patient's autonomy, although these recent ethical developments have been responsible for modifications in paternalistic style and practice in ways that are almost as great as the changes in clinical practice. The current criticisms of paternalism, however, describe an old model and use outdated examples; many of these transgressions are no longer common.

\section{Keywords}

Paternalism; patient autonomy; beneficence; medical ethics.
This article discusses the concept of paternalism, reviews the changes in its practice, and contrasts this modern form of paternalism with patient autonomy. Although a new term might be considered to reflect this modern approach, the word paternalism captures the notion of benefit to the patient as the most important part of the doctor-patient relationship. Although pejorative associations are attached to this term, (apparently as a consequence of stereotyped images), paternalism may be more ethically persuasive than the current philosophical literature suggests.

\section{History}

Paternalism has been defined as interference with a person's liberty of action justified by reasons referring exclusively to the welfare, good, happiness, needs, $?$ interests or values of the person being coerced' (1). Medical paternalism is defined similarly as interference by the physician with the patient's freedom of action, justified on the grounds of the patient's best interests.

Examples of paternalism are easy to find early in the oncology literature. The results of a survey reported in 1961 indicated that almost 90 per cent of physicians withheld diagnostic information from cancer patients because of the possibility that the knowledge would have an adverse effect on the patients (2), and more specifically, surgeons have suggested that patients not be informed of the nature of seriously mutilating procedures, such as hemipelvectomy, until immediately before the operation because the patients, with more time for consideration, might refuse a potentially life-saving procedure (3).

Although such paternalistic methods were commonly accepted in the past, they do not reflect current practice. Nevertheless, they are offered as examples of present-day paternalism, which is then criticised in much of the current philosophy literature (4). A recent survey, however, showed that 97 per cent of physicians preferred to tell cancer patients their diagnosis (5) and hemipelvectomy for osteosarcoma is now performed much less frequently in favour of limbsparing procedures. Criticisms based on the assumption that paternalistic physicians do not inform cancer patients about their diagnoses (6) are largely outdated. Although these changes might be 
interpreted as a swing away from paternalism towards patient autonomy, they can also be viewed as a continuation of the practice of providing what physicians believe to be best for the patient in the light of new knowledge.

Criticisms of paternalism generally follow one of several lines. The argument most often advanced claims that physicians cannot and do not know enough about their patients' wants, needs, interests, hopes and fears to make decisions for them (6). Modern physicians themselves, however, agree that this barrier exists and, whatever their philosophical position, constantly strive to improve communication with their patients. Another argument often used is that the physician's own motives and self-interest may come into conflict with the best interests of the patient (7), and many anecdotal examples have been given to establish this point (8). These anecdotes serve merely to inflame the reader's feelings. The observation that some physicians have weaknesses in their character can be used to condemn their behaviour but has no relevance to paternalism. If selfish acts are justified on the basis of paternalism, then rhetorical subterfuge may be added to the charge of selfishness, but paternalism itself is not at fault. The most important criticisms against paternalism focus on the question of whether the principle of respect of person has priority over the principle of beneficence $(9,10)$. This argument and the history of the general acceptance of autonomy over beneficence are beyond the scope of this paper.

These criticisms must be reviewed against the background of changes that have occurred in paternalistic behaviour because of the changes in medicine, society, sociological studies, law, and ethics and in response to these criticisms. All of these changes increase the probability of achieving the purpose of paternalism (that is, doing what is best for the patient).

\section{The changing practice of medicine}

Changes in the science of medicine have modified paternalism in several ways. The availability of more than one effective therapy (as the choice between radiation therapy or surgery for early carcinoma of the larynx) dictates that therapeutic decisions be made with consideration for the special circumstances of the patient (11). For example, the physician might choose to treat a salesman with radiotherapy to spare his voice, and to treat a cook with surgery to spare the ability to taste. Also, technological advances, such as the artificial heart, bone marrow transplantation, and renal dialysis, have caused physicians to confront a number of ethical issues and, particularly, to reassess what is best for a patient. Finally, with life support available for terminal patients, the value of sustaining life as the ultimate good has rightly been questioned. These changes mean that what is 'best' for the patient varies from patient to patient - in part, because of the different values held by each patient.
Many current treatments require the patient's active co-operation. To ensure that the patient performs $\overrightarrow{\overline{\vec{D}}}$. breathing exercises postoperatively, returns to the hospital if fever develops after chemotherapy, or $\Rightarrow$ completes a course of oral antibiotics, the physician $\stackrel{\text { ? }}{?}$ must provide him or her with sufficient information to을 understand why co-operation is essential. Thus, $\frac{\bar{F}}{\bar{N}}$ medical changes have modified the concept of what is best for a patient and have made it necessary actively to $\varrho$ enroll the patient in his care.

Society has experienced the same changes that affect $\vec{\circ}$ the practice of paternalistic physicians. Civil rights, woman's equality movements, and consumerism have $\vec{\omega}$ all emphasised the desire of people to be treated as self - S determining agents. Well-informed patients themselves may now suggest other treatment possibilities or may at least express their opinions as to how they would like to be treated. As a consequence of patients demanding a more active role in their own ${ }^{\infty}$ care, physicians have become aware that patients mayo refuse necessary treatment when they feel that theirprerogatives are being usurped. This risk must be? considered in all medical decisions.

Psychologists and sociologists have demonstrated 3 that benefits accrue when patients are involved in their@ own care (12). Ensuring that patients are informed provides protection against untoward consequences. Using surveys, psychologists have indicated wh patients want from their physicians; this informationo enables physicians to modify their behaviour so as satisfy their patients. Further, studies are beginning too examine various behavioural questions regarding theo physician-patient relationship. Well-designed studies@ are needed to answer the question of whether $\overrightarrow{0}$ informing cancer patients of their diagnosis leads to 3 suicide or other serious harm so that the decision to telle them can be based on information rather than speculation.

Numerous decisions by the courts and legislature have caused physicians to modify their behaviour. $\frac{3}{3}$ Massachusetts (13) and California (14) now have laws. requiring patients with breast cancer to be providedo with 'complete information on all alternative treatments which are medically viable' (13). A numbers of cases (15) have affirmed the obligation to take a patient's views into account in making decisions, and? have reminded physicians about the controversian nature of what is best for a patient. The law has also set limits on paternalistic actions; physicians generally may not initiate treatment without the patient'sw informed consent. Finally, the case of Truman Thomas (16), in which a physician lost a suit broughe by the family of a patient who died of cervical cancero after refusing a Pap test, has defined an obligation that physicians warn of the dangers of refusing recommended diagnostic procedures as one of the्ष necessary elements in proper medical care.

The recent emphasis on ethics has stimulated physicians to explore the ramifications of their actions They may consult the literature when they encounter 
difficult or unusual ethical problems in the same manner as when they confront unfamiliar diseases.

Earlier criticisms of paternalism questioned the doctor's motives. Now, physicians try to be aware of their motivations as well as those of their patients, and since different physicians and different patients may hold disparate views of what is best, the modern paternalistic physicians has well learned the need to explore the differences among individual patients.

\section{Modern paternalism}

How does today's paternalistic physician operate while being influenced by so many forces? The guiding principle of modern paternalism remains that the physician decides what is best for the patient and tries to follow that course of action. The notion that doing what is best for the patient can be determined from only the physician's values is antiquated - an approach as ineffective as arsenicals in syphilis. A more homogeneous culture in the past allowed physicians to assume that they shared values with their patients, but in a pluralistic society, the patients' views can never be assumed. Today's physician must ascertain the values and interests of the patient. Omission of this step is a betrayal of the fundamental principles underlying modern paternalism.

The simplest approach to learning the patient's values is to ask him what he wants. To expand this information, general discussions with the patient, or with friends and family of the patient, will be of help. This thoughtful probing has always been an important part of good medical care (17) and is mandatory for the modern paternalist. This information is now used to determine what is best for the patient in addition to establishing rapport, making a diagnosis, improving communication, and offering support. Discussions about cardiopulmonary resuscitation with all patients who are seriously ill permit the doctor to determine what a patient prefers; such discussions have become routine at many hospitals (18).

After determining what is best for the patient, the physician must implement the plan. Because active patient participation produces better results, he will usually inform or instruct the patient. His goal is to improve care rather than promote patient autonomy. Gert and Culver (19) presented the case of a physician who acted paternalistically by confronting a patient who had breast cancer with the truth.

If the patient will do better believing he is in control the physician should encourage this belief and indirectly facilitate the right choice of action. Usurping a patient's autonomy merely to allow the physician to retain control represents authoritarianism, not paternalism. Over 50 years ago, H L Mencken (20) wrote that some physicians 'conceive it to be their duty to force their advice upon everyone, including especially those who don't want it. That duty . . . is born of vanity, not of public spirit. The impulse behind it is not altruism, but a mere yearning to run things'. Paternalism, in which a patient's freedom is lessened for the patient's ultimate benefit, should not be confused with authoritarianism, where this freedom is lessened for the physician's power.

In most circumstances, the results of treatment will be similar for either the modern paternalism or the patient-autonomy model because both physician and patient want what is best for the patient. In situations where options appear equal to the physician, no reason exists to deny the patient the decision-making if he wants it. So, we must ask, under what circumstances, if any, does modern paternalism offer advantages to the competent adult patient? First, many patients choose immediate gratification over possible long-term benefits, even though they realise that the latter course is better for them. For example, a young man with curable testicular cancer may wish to avoid the temporary but severe nausea produced by chemotherapy. This situation justifies and even requires the physician's encouraging, or if necessary, coercing the patient to complete the therapy.

Second, formal decision-analysis is unfamiliar to most patients, whereas physicians are trained in problem-solving. Thus, armed with adequate information about a patient's values, the physician may be in a better position to decide effectively what is best for the patient than the patient even if he has been informed of all the medical information and then makes his own decision. Although understanding a patient and his values fully may be difficult (and perhaps impossible) for the physician, patients may find understanding either the scientific basis for their treatment or the underlying motivations that influence their own decisions equally difficult. Finally, the physician is likely to be more objective about the patient than the patient will be about himself.

Practising modern paternalism is difficult. The problems stem not from restrictions in the law or from refusal by patients but from the great difficulty in empathising with another person to the extent of safely determining his best interests. Empathy or good intentions alone are insufficient; the modern paternalistic physician must also have the medical expertise to make the decision. Further, making decisions is often more difficult than relinquishing the decision-making to the patient. Finally, no matter how expert the physician is and how conscientious in his paternalism, the results of treatment are not always predictable and for some patients may not prove optimal. Of course, the physician must also be selfless and not use the patient's 'best interests' as an excuse for his own greed, egotism or laziness.

The concept of patient autonomy emphasises procedure and the right of patients to decide for themselves; modern paternalism emphasises outcome and the principle of patients' best interests. An important difference between autonomy and paternalism is the weight given to patients' values. Autonomy considers patient values as decisive. Modern paternalism considers these values as only one factor among others weighed by the physician in 
making a decision. Each posture has advantages and disadvantages. Failure of either to work in some situations does not necessarily invalidate it for others. Criticisms based on an antiquated image of the paternalistic physician, however, have no value. Paternalism needs to be evaluated logically, and any forceful critique must examine the practices and principles of modern paternalism.

Gary B Weiss MD PhD is Clinical Associate Professor of Medicine and of Human Biological Chemistry and Genetics at the University of Texas Medical Branch at Galveston.

\section{References}

(1) Dworkin G. Paternalism. Monist 1972; 56: 64-84.

(2) Oken D. What to tell cancer patients: a study of medical attitudes. Fournal of the American Medical Association 1961; 175: 1120-1128.

(3) Miller T R. One hundred cases of hemipelvectomy: a personal experience. Surgical clinics of North America 1974; 54: 905-913.

(4) Thomasma D C. Beyond medical paternalism and patient autonomy: a model of physician conscience for the physician-patient relationship. Annals of internal medicine 1983; 98: 243-248.

(5) Novack D H, Plumer R, Smith R L, Ochitill H, Morrow G R, Bennett J M. Changes in physicians' attitudes toward telling the cancer patient. Fournal of the American Medical Association 1979; 241: 897-900.

(6) Buchanan A. Medical paternalism. Philosophy and public affairs 1978; 7: 370-390.

(7) Millman M. The unkindest cut: life in the backrooms of medicine: New York: Wm Morrow and Co, Inc, 1977.
(8) Kassirer J P. Adding insult to injury: usurping patients' prerogatives. New England journal of medicine 1983; 308 $\stackrel{\bar{\partial}}{\text {. }}$ 898-901.

(9) Childress J F. Who should decide?: paternalism in health: care. New York: Oxford University Press, 1982.

(10) Clements C D, Sider R C. Medical ethics' assault upono medical values. Fournal of the American MedicaE Association 1983; 250: 2011-2015.

(11) McNeil B J, Weichselbaum R, Pauker S G. Speech an survival: tradeoffs between quality and quantity of life in laryngeal cancer. New England journal of medicine 1981 ( 305: 982-987.

(12) Dodd M J. Measuring informational intervention for chemotherapy knowledge and self-care behaviour. $\vec{\omega}$ Research in nursing and health 1984; 7: 43-50.

(13) Annas G J. Breast cancer: the treatment of choice Hastings Center report 1980; 10(2): 27-29.

(14) Carter S K: The California breast cancer law and government-mandated patient education. $C A:$ a cancer $_{\perp}$ journal for clinicians, 1982; 32: 173-176.

(15) Gutheil T G, Appelbaum P S. Substituted judgment: $\stackrel{\oplus}{\oplus}$ best interests in disguise. Hastings Center report 1983은 13(3): 8-11.

(16) Gargaro W J. Cancer nursing and the law: informed $\vec{b}$ refusal: part IV. Cancer nursing 1980; 3: 467-468.

(17) Peabody F W. The care of the patient. Fournal of the American Medical Association 1927; 88: 877-882.

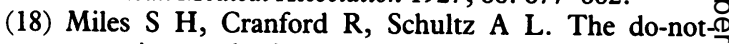
resuscitate order in a teaching hospital: considerationsand a suggested policy. Annals of internal medicine $198 \%$ 96: 660-664.

(19) Gert B, Culver C M. Paternalistic behavior. Philoso and public affairs 1976; 6: 45-57.

(20) Mencken H L. Christian Science. Baltimore Evening Sun 1927 Feb 28. Reprinted in: Mencken H L, ed. $A$ Oे Mencken chrestomathy. New York: Alfred A Knopf, 1956: 342-346.

\section{Institute news and notes}

Professor R B Welbourn, Emeritus Professor of Surgical Endocrinology, and Chairman of the Governing Body of the Institute of Medical Ethics has received an honorary DSc from the Queen's University of Belfast. 